\title{
UNA APROXIMACIÓN A LA NUEVA RETÓRICA DEL LÍDER POLÍtTICO TELEVISIVO: ACCIONES, CUALIDADES Y DISCURSO
}

\author{
SALOMÉ BERROCAL \\ Profesora Adjunta de Teoría de la Comunicación y Teoría de la Información. Universidad San Pablo-CeU de Madrid
}

\section{Resumen}

Este artículo realiza una aproximación a la figura del líder político actual, por tanto intenta dar respuesta a preguntas tales como: ¿a quién asignamos hoy el término de líder político? o ¿qué es el liderazgo político? El líder necesita el reconocimiento de un grupo o parte de la mayoría. En nuestras sociedades actuales, el liderazgo existe en función de la comunicación, de la visibilidad. Los candidatos que más presencia mediática tienen gozan de mayor probabilidad para convertirse en los más célebres. La recepción de la imagen y su interpretación por parte del público, se convierte en un mecanismo clave en la comunicación política. El marketing político establece las acciones, el discurso y las cualidades que debería presentar el candidato con el objeto de transformarlo en el líder perfecto, establecido en cada contexto por la opinión pública.

\section{Palabras clave}

Liderazgo político, líder político, personalización política, marketing político, comunicación política.

\section{Abstract}

This article analyses the current figure of the political leader and hence tries to come up with answers to such questions as: on which type of person nowadays do we pin the term of political leader? What is political leadership? Leaders need the recognition of a majority group or party. In today's societies leadership depends on communication and visibility. Candidates with the highest media profile are the most likely to become famous. Reception and interpretation of the image by the public at large becomes a key mechanism in political communication. Political marketing establishes the actions, the discourse and qualities needed by candidates to transform them into the perfect leader as established in each particular context by public opinion.

\section{Key Words}

Political leadership, political leader, political personalisation, political marketing, political communication. 


\section{INTRODUCCIÓN}

El liderazgo en el lenguaje político es un término estrechamente relacionado con el carisma. El uso político de este segundo concepto, el carisma se lo debemos al sociólogo alemán Max Weber (1864-1920), que lo definía como "una cualidad extraordinaria de una personalidad en virtud de la cual ésta es considerada como poseedora de poderes y cualidades sobrenaturales o sobrehumanos, o cuanto menos excepcionales, no accesibles a los demás" (Weber, 1968: 240).

En la actualidad, en las democracias occidentales, "el carisma es algo diferente, más cercano a la popularidad, los candidatos no pretenden destacar por encima del ciudadano común, más bien al contrario: el líder político debe presentarse como alguien corriente, no distanciado del resto. Triunfa quien representa los intereses del grupo, quien puede presentarse como parte de la mayoría" (Martín Salgado, 2002: 86-87).

El líder, como se ha señalado anteriormente y como indica la RAE, es la persona a la que un grupo sigue reconociéndola como jefe u orientadora. Necesita, por tanto, el reconocimiento de un grupo o parte de la mayoría. Martín Salgado afirma que en el uso cotidiano del término a veces confundimos liderazgo con autoridad, es decir hablamos del líder de un partido simplemente porque lo dirige. Ocupar un cargo no significa ser un líder. El liderazgo existe en función de la comunicación y sólo se demuestra a través de las conductas comunicativas. No basta con querer ser líder o creerse líder, para que exista auténtico liderazgo tiene que haber alguien que lo reconozca como tal.

Hay distintas tipologías de liderazgo en política: el líder ideológico que define objetivos y busca reformas, el líder transaccional que gestiona y que es especialmente eficaz en momentos de estabilidad, o el líder carismático que suele surgir en tiempos de crisis y se fundamenta en lo emocional. Pero si tuviéramos que referirnos a una sola categoría de liderazgo, que triunfa en el actual sistema comunicativo, la mayoría de los autores consultados apuntan al líder "transformador": "aquel que tiene visión, ideas propias, sabe inspirar a los demás y persuadir al electorado. Un líder transformador apela tanto al intelecto como a las emociones de su auditorio, con temas sencillos y memorables como "cambio", pero también con ideas de fondo que explican a qué responden esos temas" (Martín Salgado, 2002: 92-93). J. Séguéla nos ilustra en este sentido, tras poner en marcha la campaña electoral que condujo a François Miterrand a la presidencia de la República, "Dos carteles reducirían el programa socialista a su expresión más simple, pero también la más rotunda: "Lo primero es el empleo"... y "Vivir de otra manera"... El mensaje político y el mensaje psicológico se fundían en uno (Séguéla, 1982: $31-32)$.

Hoy, el concepto de líder político se aproxima a una figura capaz de movilizar a los demás a través de sus llamamientos a lo racional y a lo emocional. Pero, ¿̇desde cuándo se impone esta condición de liderazgo? 


\section{LA PERSONALIZACIÓN DE LA POLÍTICA}

La consideración del candidato como un factor indiscutible en la decisión de voto es un fenómeno relativamente reciente. Los primeros estudios electorales, correspondientes a los años 4060 (Lazarsefeld, Berelson, Gaudet, 1944; Lazarsefeld, Berelson, McPhee, 1954) no dedicaban apenas atención a los candidatos y su influencia en las decisiones electorales. En esas fechas, en que se mantiene la teoría de los Efectos Limitados de los medios, la televisión no es aún una herramienta electoral relevante y las elecciones se ganan gracias a las maquinarias de los partidos y al trabajo de calle con los voluntarios. Los resultados de estos trabajos apunta a una influencia en que los medios cristalizan o refuerzan más que convertir opiniones.

Es, a partir de la publicación de obras como The American Voter (Campbell y otros, 1960) cuando se empiezan a considerar las características personales de los candidatos como un factor más que influye en la decisión de voto, junto al partido y los temas o issues ¿Qué ha cambiado? Por una lado las investigaciones en torno a la influencia de los medios reciben una orientación distinta: en los trabajos se plantea el estudio de los efectos a largo plazo en el conjunto de la sociedad, no en el individuo en particular, y los medios de comunicación se miden por su actividad informativa, más que persuasiva. Esta nueva orientación lleva a los autores a centrar su atención sobre los efectos cognitivos de la comunicación política, es decir, que los medios dan información a la gente y su efecto es el de la información. Pero además, en los años 60 nace un nuevo tipo de campaña electoral, en la que ha irrumpe un nuevo medio de comunicación: la televisión. Se producen los primeros debates entre candidatos (Nixon y Kennedy') y el análisis que se hace de estos debates dirige a distintos tipos de conclusiones a los teóricos: hay quienes siguen con la idea de una exposición selectiva (el efecto ha sido refuerzo), otros hablan de un sector al que llaman mayoría intrigante son los que contestan que le han gustado los dos candidatos (ahora están indecisos). Hay otros que inician una nueva orientación (eran partidarios de un candidato y después del debate han cambiado de posición).

Cabe reseñar el diferente impacto que tuvo el debate sobre el electorado en aquellos que lo siguieron por televisión respecto a los que lo hicieron por la radio. Estos últimos seguían dando co-

\footnotetext{
"Nixon tuvo en su contra una nefasta puesta en escena que exhibió ante los telespectadores convertidos en electores. Frente a él, estaba un hombre joven, atractivo, de dicción brillante y con un programa romántico basado en las tradiciones del país. Kennedy con su estilo distinto encandiló y conquistó muchos votos desde el principio del debate, su actuación técnica y profesional estuvo muy bien preparada, y ganó. Este primer debate fue para algunos especialistas clave en el triunfo de Kennedy en las elecciones. Fue concebido como antológico y de ahí se explica el valor de mito que se le ha conferido dentro del campo de las campañas electorales y de la comunicación política. Kennedy ganó el primer debate frente a Richard Nixon pero en el cómputo general de los cuatro debates los sondeos otorgaban un empate, ya que la población pensó que los dos candidatos estuvieron iguales en dos de los debates $\left(2^{\circ}\right.$ y $\left.4^{\circ}\right)$, y de los otros dos, uno fue concedido a Kennedy (1 9 ) y otro a Nixon (3\%). Cinco días después del último debate, los dos candidatos estaban empatados con un $48 \%$, lo que minimiza el impacto real de los debates en la votación. Si hubo influencia en el voto fue pequeña y en cualquier caso no se le puede otorgar la elección de Kennedy exclusivamente al éxito que tuvo por su actuación ante las cámaras en los debates. Lo que es incuestionable es que salió más beneficiado después de ellos, ya que mejoró su imagen en unas elecciones que se decidieron por menos de cien mil votos (Kennedy 50'1\% - Nixon $49^{\prime} 9 \%$ ), una muestra ínfima para el electorado de los Estados Unidos en esos momentos pero suficiente para que Kennedy se proclamara presidente. Su contrincante perdió, posiblemente si no hubiera aceptado el reto hubiera llegado a ser presidente" (Marín, 2003: 218).
} 
mo favorito a Richard Nixon de cara al triunfo final pero los que lo vieron por televisión otorgaban la victoria a Kennedy. La razón estribó en que no era el discurso verbal el que había modificado la relación con los candidatos sino la imagen. El mismo discurso, las mismas promesas, el mismo contenido en cuanto a cada tema daba como vencedor a un candidato si lo había escuchado por la radio, o a otro si lo había visto por la televisión.

A partir de ese momento nace en la comunicación política el concepto de la personalización. En los años setenta y ochenta, tercera fase del estudio de las conductas electorales, empieza a sugerirse que las elecciones son resultado de las evaluaciones que los votantes hacen de los candidatos (Agranoff, 1972). "La personalización de la política y la imagen ha engendrado un nuevo tipo de concepto y liderazgo político que se caracteriza por su visibilidad. El líder político y electoral existe para ser observado, para simbolizar acciones y propuestas de su partido o de su gobierno" (Rospir, 1999: 79).

La política ha tenido que adaptarse a un nuevo paisaje, ya no tiene un espacio propio, es el régimen mediático el que impone el escenario. "La nueva lógica de la práctica política debe bastante a lo que se podría denominar "política de visibilidad", potenciada y administrada por el sistema de comunicación...La política es hoy inviable sin la visibilidad que proporciona aquél, razón por la que los políticos han de aparecer en él si quieren dotarse de las imágenes y la notoriedad adecuadas con las que hacer frente a la competencia electoral" (Ortega, 2003: 71).

Los candidatos contemporáneos necesitan a los medios de comunicación porque el electorado observa en los mass media las informaciones y propuestas de sus dirigentes. Séguéla afirma en su libro: "Mientras el presidente saliente se dirigía, en la Porte de Pantin, a millares de jóvenes en un discurso de cincuenta minutos, el futuro presidente se encontraba con unas cuantas docenas pero, en contrapartida, pasaba el día entero con ellos, confiando a los medios de comunicación la tarea de llevar su plática hasta el gran público" (Séguéla, 1982: 36).

La influencia de estos medios, en especial de la televisión, es importante en la adquisición de conocimientos del electorado y en su decisión sobre quién debe gobernar. "Más que el Parlamento, la televisión es el gran foro público donde se debate lo que a todos atañe y donde se libran las batallas por el poder. El acceso y el control de los medios son en la actualidad el máximo recurso estratégico, y por tanto los líderes como los partidos políticos consideran a los tiempos y espacios que logran ocupar en los medios como las divisiones con que cuentan para vencer a sus adversarios. Porque la televisión ya no es sólo la cancha en la que se dilucidan las batallas políticas, sino también el arma que se utiliza para asegurarse la victoria en las mismas" (Muñoz-Alonso, 1999: 16).

La televisión tiene un indudable poder determinando qué noticias, qué asuntos $y$, en especial, qué candidatos deben recibir una cobertura diaria. La política televisada atrae audiencias como ningún otro medio, es el soporte fundamental de la información política y consigue introducir en los hogares de los ciudadanos, con escaso tiempo, las imágenes de los aspirantes en la carrera política. De ahí, que con independencia del sistema electoral y de partidos de que se trate, la televisión sitúa al líder en el centro de la comunicación política. 


\section{EL LÍDER POLÍTICO TELEVISIVO}

Los candidatos que obtienen mayor cobertura mediática tienen mayor probabilidad de convertirse en los más célebres y las características personales o cualidades, que más a menudo destaca la información periodística, son también las que con mayor probabilidad citarán los electores en su descripción del candidato. "De la misma forma que se puede concebir un elenco de temas de atención posible ante unos comicios, es posible pensar también en términos de catálogo de candidatos clasificados conforme a la cantidad de cobertura periodística que reciben, así como respecto a un listado de las características o cualidades más subrayadas de esos candidatos" (Weaver, 2003).

El ciudadano medio carece del tiempo, conocimiento, capacidad y motivación necesarios para seguir las argumentaciones complejas. Por eso utiliza "atajos cognitivos que reducen los enormes costos que comporta adquirir, procesar y evaluar todos los mensajes necesarios para votar informadamente" (Popkin, 1990: 17-35). El gobernado actúa con pereza atendiendo sólo a unas cuantas señales o imágenes que difunden los medios. La recepción de la imagen, proyectada por el canal televisivo, y su interpretación por parte del público, se convierte en un mecanismo clave en la comunicación política.

¿En qué modelo o ideal de liderazgo pone el electorado sus expectativas? En el inicio de esta aproximación al concepto del líder político actual, hemos mencionado una categoría de liderazgo hacia la que apuntan la mayoría de los teóricos: el líder transformador, aquél que no sólo realiza llamamientos a lo racional, sino también a lo emocional. El liderazgo de la visibilidad, de la persuasión y las llamadas a lo emocional, ha solapado al liderazgo de la pedagogía política y de la argumentación lógica, tras el nacimiento de la televisión. La personalización de la política, ejecutada sobre este liderazgo, ha conseguido desplazar a los partidos del papel preeminente que jugaban en las campañas y en la decisión de voto. Con independencia del sistema electoral y de partidos de que se trate, el candidato recibe hoy una atención informativa -un seguimiento- y emplea unas estrategias y recursos comunicativos con los ciudadanos que son comunes en todas las campañas. Para conseguir alcanzar el liderazgo, ser alguien capaz de movilizar al resto, hoy se necesita un conocimiento y un dominio del medio audiovisual.

Los debates electorales en 1960 entre Richard Nixon y John Kennedy, antes citados, supusieron, no sólo un cambio a la hora de estudiar los efectos provocados por los medios en la audiencia sino también, la apertura a un nuevo tipo de influencia provocada por la imagen televisiva. El mismo Nixon, en su libro Seis Crisis, afirma que la derrota electoral se debió en gran medida a que no supo estar en este nuevo medio: "Dediqué demasiado esfuerzo a la sustancia del mensaje, y demasiado poco al especto. Me fijé mucho en lo que tenía que decir y poco en cómo" (De Cora, 1991: 37).

Veinte años más tarde, la historia volvía a repetirse. "Para los que siguieron el debate la noche del 28 de octubre de 1980 entre Carter y Reagan, parecía que Carter hubiera ganado con 
una facilidad pasmosa. Dominaba los hechos y los detalles. Sus respuestas fueron más sólidas, y daba la impresión de que tenía a Reagan a la defensiva. Sin embargo, la impresión de los telespectadores fue totalmente distinta. Reagan tenía más aspecto de presidente que el propio Carter. Después de los nervios del principio, se sintió a gusto y se relajó más rápidamente. Carter, por el contrario, parecía nervioso todo el tiempo y, al igual que Nixon dos décadas antes, daba la sensación de estar inhibido y crispado ante su oponente. Estuvo serio y frío, mientras que Reagan fue capaz de sonreír, a veces con amabilidad y otras con picardía" (Perry, 1986: 122).

Walter Mondale también sufrió la derrota ante el candidato Reagan y después de la apabullante victoria de éste dijo: "Creo que en la política moderna se necesita un dominio de la televisión mayor que el que yo podía alcanzar. Creo que ya saben ustedes que nunca me entusiasmó la televisión. Y para decir toda la verdad, ella tampoco se entusiasmó nunca por mí (...) Creo que ya no va a ser posible presentarse para la presidencia si no se es capaz de crear confianza y comunicación todas las noches. Así es como se habrá de hacer"(Perry, 1986: 192).

\section{ACCIONES, CUALIDADES Y DISCURSO DEL LÍDER POLITICO TELEVISIVO}

La distinción entre la influencia de factores cognitivos y afectivos en la percepción de las personas está rodeada de polémica: hay quienes creen que las reacciones que tienen los votantes respecto a los líderes políticos son esencialmente emocionales, basadas más en el aspecto que en las políticas, $y$, por otro lado, hay quienes ponen el énfasis en factores racionales y sugieren que los votantes se guían principalmente por las políticas y los datos objetivos. Desde mi punto de vista, todos los tipos de información que los votantes reúnen sobre un líder influyen potencialmente en la formación de la "imagen" del candidato y pueden contribuir a su decisión final. Asimismo, cada votante reacciona de distinta manera al mismo tipo de información.

Las acciones, el discurso y las cualidades que trata de presentar el candidato cumplen un objetivo: aproximarse al modelo del líder perfecto.

\section{Acciones}

La llegada del color a la televisión, de la música, de los coros, del vídeo, etc., conlleva la necesidad de que los políticos aprendan a incorporarse a todas las exigencias de la producción y el guión. Cambios en la forma de vestir, de hablar, de peinarse o retoques estéticos más o menos oficiosos, están en el anecdotario de esta ineludible práctica de nuestro días.

El marketing político trabaja sobre la imagen del político que se quiere transmitir. Dos ejemplos de ello son las estrategias planteadas por Trent y Friedenberg en su libro sobre las campañas de comunicación política, donde indican que dependiendo de la posición en la que parta el candidato en unas elecciones así deberá actuar. 
La estrategia pragmática del gobernante supone la creación de "pseudoeventos" para atraer y controlar la atención de los medios, fomentar las comisiones para investigar áreas públicas, presentarse consultando o negociando con líderes del mundo, recibir la aprobación del partido y de otros importantes líderes sociales, enfatizar los cumplidos, crear y mantener una política de trincheras, interpretar e intensificar los problemas de la política internacional.

El estilo del contrincante puede ser definido, en sus estrategias de comunicación, como el diseño de una campaña de persuasión destinada a convencer a los votantes de que el cambio es necesario y que el contrincante es la mejor persona para conseguir ese giro. Sus estrategias son las siguientes: atacar el discurso de los oponentes, adoptar una actitud ofensiva en determinados asuntos, realizar llamamientos hacia una necesaria transformación, enfatizar el optimismo hacia el futuro, oponer a los valores tradicionales los valores del cambio, representar la filosofía de centro del partido político y delegar en otras personas del partido los ataques duros en un esfuerzo para controlar la retórica demagógica.

\section{Discurso}

La escasez de grandes diferencias ideológicas entre los partidos a la hora de dirigirse al electorado, y la necesidad de comunicarse con el pueblo a través del medio que mayor audiencia consigue, conduce a los expertos en marketing político a intentar controlar el discurso en televisión: "Los media son libres: la prensa gráfica, escrita o los medios audiovisuales no se pueden controlar, pero lo que sí podemos controlar son dos cosas el discurso que emite el poder, y no sólo el contenido sino la imagen del líder político que emite este discurso: Pero aún es necesario ir más allá. El reto es controlar la imagen que van a recibir de los medios que son libres" (Ramonet, 1994: 22).

Además del marketing político, existe otra novedosa fórmula para controlar la imagen que de los partidos y candidatos recibe el electorado son los llamados "gabinetes de prensa" o "gabinetes de comunicación". Como señala F. Ortega (2003), un gabinete de esta naturaleza se caracteriza por la función de mediación que cumple entre los políticos y los periodistas. No son ya los políticos quienes se dirigen a los periodistas encargados de elaborar noticias; entre ellos colocan a otros periodistas encargados de elaborar las imágenes que de los políticos deben hacer llegar a los periodistas que trabajan en los medios de comunicación.

McGinnis señala que el político de televisión no puede pronunciar un discurso: debe enfrascarse en una conversación íntima. No ha de presionar jamás. Debe sugerir, no afirmar; debe implorar, no exigir. Displicencia es la palabra clave. Una displicencia cuidadosamente estudiada. Entusiasmo y franqueza son convenientes, pero han de manejarse con gran discreción. Sin filtrar, pueden ser fatales (McGuinnis, 1972: 30).

Un ejemplo clásico de lo que puede suponer el conflicto entre las palabras y las pistas visuales en una campaña política ocurrió en 1988, en el debate entre los candidatos George Bush y Michael 
Dukakis. El presentador de la cadena CNN, Benard Shaw, moderaba el debate e hizo la primera pregunta al candidato demócrata: "Si Kitty Dukakis (la esposa del candidato) fuese violada y asesinada, ¿̇apoyaría usted la pena de muerte irrevocable para su asesino?". Dukakis respondió que, aún así, él se opondría a la pena de muerte. Ofreció argumentos razonables y, sobre todo, racionales. Su respuesta, sin embargo, fue muy comentada y criticada, no por su contenido, sino por la frialdad con que la ofreció. Según cuentan los psicólogos Cimbrado y Leippe (1991), "Dukakis no expreso ninguna emoción ante la idea de su esposa enfrentándose a ese horrible destino (...) Independientemente de cómo se sintiese, no había ninguna emoción en su voz, ninguna muestra de dolor en su cara. El público se vio obligado a preguntarse: ¿dónde está la pasión detrás de la lógica? ¿Qué tipo de hombre es éste? Sin duda, un hombre muy bueno que sentiría un gran dolor si cualquier pena afligiese a sus seres queridos. Pero no fue eso lo que transmitió a los telespectadores; el daño a su imagen estaba hecho y esa impresión contribuyó a su caída (Martín Salgado, 2002: 104-105).

\section{Cualidades}

Recientemente, los teóricos de la comunicación han afirmado que el estilo no debe limitarse al lenguaje sino que hay que considerar la calidad que impregna todos los elementos de la comunicación individual. Siguiendo esta línea, el estilo debería incluir cada aspecto no-verbal de la comunicación -incluyendo actitud física, sonido de la voz, forma del cuerpo y sus movimientos, apariencia, ropa, y elección de la colocación- que operan como símbolos para crear formas que interfieren en el intercambio comunicativo.

Los anuncios televisivos, que presentan a los candidatos en distintas situaciones, están claramente diseñados para conseguir o mantener cierta percepción sobre el líder. Las imágenes políticas, sin embargo, son más complejas que simples estrategias ideadas para presentar el candidato a los votantes.

Las imágenes deberían ser también consideradas en términos de las impresiones que los votantes obtienen -que creen que es verdadero o falso, deseable o indeseable- de los aspirantes en la campaña. La imagen es "más que el mensaje proyectado por el candidato o que la película creada para el votante. La imagen es una evaluación negociada y construida por los candidatos y votantes en una aventura compartida" (Louden, 1990: 1). En otras palabras, las creencias que los votantes tienen acerca de los candidatos están basadas en una interacción o interdependencia sobre lo que los candidatos hacen y la respuesta evaluada que hacen los votantes sobre ellas: "transacción entre los candidatos y los votantes".

Estas cualidades o atributos personales tienden a forjar sobre cada líder características como la competencia, experiencia, paciencia, precaución, capacidad de decisión y valentía, y junto a ellas aspectos personales, como resistencia, honestidad, justicia, mente abierta, seguridad, energía y atractivo físico. El electorado no quiere elegir a alguien que es percibido como deshonesto, torpe, injusto, inmoral, corrupto o incompetente. 
Los electores, más que ideologías o programas, eligen a los partidos políticos a través de la opinión que tienen de sus candidatos, ya que éstos son los guías y cabezas visibles de la comunicación política que se establece. Los partidos se convierten, tras el escenario de la campaña electoral, en meras máquinas de ganar elecciones, y para ganar en unas votaciones se, hace necesaria una imagen que identifique al partido ante el electorado. Una imagen que será presentada, 0 representada sobre el escenario, por el líder o cabeza de lista elegido por el partido político, teniendo en cuenta el carácter telegénico que es necesario adoptar.

"Nuestras vinculaciones afectivas a las cosas, y muy especialmente a las personas determinan gran parte de nuestra conducta. Por eso, las vinculaciones afectivas a determinados objetos de nuestra vida cotidiana, a ciertos productos, a ciertas instituciones, grupos y líderes, son tan gratificantes y crean lazos a menudo muy sólidos que definen nuestro comportamiento. El factor emocional -al que pertenecen en gran medida las motivaciones y la autoimagen- ejercen un poder decisivo en nuestras imágenes mentales, y en consecuencia, en nuestras opiniones y en nuestras conductas activas" (Costa, 1992: 125).

Las diferentes investigaciones llevadas a cabo, sobre la influencia de la imagen del partido en el electorado, coinciden en señalar tres valores que inciden de forma notoria en el público: la credibilidad, el atractivo y el poder de la fuente.

* La credibilidad de la fuente es citada como agente de persuasión por autores como Hovland y Janis, que afianzaron la existencia de dos subfactores integrantes de la credibilidad: la competencia o pericia y la fiabilidad ética. En 1953, un estudio de Hovland junto a Janis y Kelley (1953) ratifica que la mayor credibilidad de la fuente facilita la persuasión del mensaje en grado más alto al de una fuente "neutra" y ésta, más que otra de baja credibilidad. La credibilidad es la piedra de toque de la persuasión, condición sine qua non para tener éxito en la comunicación de un mensaje. Un mensaje apropiado, atractivo y coherente comunicado por un portavoz de escasa credibilidad carece de eficacia. Por el contrario, un portavoz que disfruta de un nivel de credibilidad alto compensa a menudo las debilidades del mensaje.

La credibilidad, siguiendo la perspectiva deductiva, se consigue cuando se dan en la persona del comunicador dos factores: experiencia y honradez. En cambio, la perspectiva inductiva, representada por McCroskey (1972: 78), define la credibilidad como una actitud del receptor hacia el comunicador.

Los especialistas del marketing electoral intentan reforzar la credibilidad de su candidato haciendo constar precisamente que son personas honradas, preparadas, que saben de lo que están hablando. Existen distintas estrategias a través de las cuales los líderes políticos intentan transmitir este tipo de honradez. Una de las más frecuentes es invitar a la prensa a investigar su pasado, incluyendo su vida privada, afirmando que "no hay nada que ocultar", o dando a conocer su situación económica. También, se ha demostrado que cuando el comunicador parece estar actuando contra lo que se percibe como su propio interés, o al menos cuando no lo persigue directamente, refuerza su credibilidad. 
El dinamismo como factor de credibilidad lo identificaron Berlo, Lemert y Mertz (1969), afirmando que un comunicador con una elevada tasa de dinamismo sería descrito por el auditorio como fuerte, enfático, franco, contundente, activo, enérgico, vigoroso... Mientras que un comunicador que careciese de este factor sería descrito como dócil, flemático, pánfilo y vacilante. Los políticos encuentran maneras muy diversas para comunicar su dinamismo al electorado. Por ejemplo, para demostrar su energía o vigor es frecuente verlos en campaña practicando su jogging matutino o algún otro deporte... Una buena parte de la campaña consiste en sonreír, estrechar manos, besar niños, estar con muchedumbres festivas y rodearse de música pegadiza, todos ellos factores que contribuyen a comunicar dinamismo, a mostrar al candidato como una persona activa y positiva (Martín Salgado, 2002: 85).

*El atractivo de la fuente: "tanto en comunicación en general como en comunicación política en particular, no son pocos los casos en que el concurso del atractivo del partido y/o líder político es definitivo, y esto, es aún más notorio, si cabe, en aquellas campañas electorales en que los restantes factores de la imagen (credibilidad y poder) no perfilan como resultante un claro partido ganador. Conviene por tanto, sin sobrestimarlas, no infravalorar tampoco esta parte de la imagen pública" (Arceo, 1982: 128-129). La cuestión de la apariencia va mucho más allá de ser guapo o vestir adecuadamente. Hay tres subfactores que saturan el efecto del atractivo de la fuente: la similitud, la familiaridad y el agrado de ésta para el receptor.

Según la "estrategia de identificación", sugerida por Burke en 1962, la fuente intenta influenciar a su audiencia comenzando por mostrar que, efectivamente, sus respectivos intereses y necesidades son mutuos. A la vista de una serie de estudios, este autor entiende que la influencia por similitud obedece a dos razones: la primera, la tendencia de las personas a que les agraden otras similares, y la segunda, el que un sujeto asuma que otro semejante utiliza los mismos criterios que él para formar su opinión. "Cuando existe una similitud ideológica del receptor con varias fuentes, y a éstas se les supone parecida credibilidad, la decisión puede ser función, en buena parte, de la posible mayor semejanza de aquél con cada uno de los emisores en características no sólo de sexo, raza o status, sino del tipo de actividades usuales, edad, o incluso de estilo al hablar, acento, vestimenta, grupos de referencia o pertenencia..." (Arceo, 1982: 133).

La familiaridad entre la fuente y su audiencia también han sido objeto de no pocas investigaciones desde la óptica de su posible influencia en los receptores del mensaje, parece probado, al menos por los trabajos realizados durante las décadas 50 y 60 , que en general el agrado interpersonal y consecutiva influencia se incrementan con la frecuencia del contacto, así como la estrechez de éste.

El agrado de la fuente, según sugieren Collins y Ashmore en 1970, puede llevar a la influencia en el receptor debido a cuatro razones: 1. Que la atracción interpersonal, por sí misma, sea posiblemente una base de influencia social; 2. Que tendemos a que nos agraden aquellos que nos recompensan o benefician, de modo que la posesión de recursos para esto probablemente causa tanto agrado como efecto social; 3. Que tendemos a estar de acuerdo con las personas que nos agradan, según la teoría de la consistencia; 4 . Que la interacción con personas agradables es una 
recompensa en sí misma, de manera que el agrado podría facilitar la persuasión multiplicando los beneficios asociados con tal interacción.

*El poder de la fuente incluye tres componentes (McGuire, 1969) mediante los cuales el poder percibido de la fuente puede afectar a la imagen que de ésta tenga el receptor $y$, consiguientemente, en la posible actitud y conducta de éste último.

El primer componente se refiere a la fórmula en que el receptor aprecie la amplitud con que la fuente puede administrar sanciones positivas o negativas. El segundo elemento es que el receptor estime si la fuente está interesada en que él esté o no de acuerdo con ella. Por último, el tercer componente es el que el receptor juzgue cuan probable es que la fuente pueda observar si la posición que ella preconiza es asumida o no.

La credibilidad, el atractivo y el poder de la fuente, a pesar de ser características independientes tienen también cierta conexión. Así lo demuestra una investigación llevada a cabo por Rosenberg y McCafferty (1987: 31 -47), con el objeto de conocer si la imagen del candidato afecta a la decisión de voto. Los autores establecieron tres hipótesis en su estudio: la primera suposición señala que si el líder tiene por sí mismo un importante impacto en el voto, aparte de su afiliación política, las cualidades personales del candidato podrían tener una influencia significativa en la decisión de voto. La segunda conjetura establece que las cualidades personales del candidato dependen de la imagen que proyecta; y la tercera presunción indica que la imagen que se difunde del candidato puede ser modelada.

El trabajo de campo condujo a los siguientes resultados: en primer lugar, el análisis sugiere que las diferentes presentaciones de una misma persona crean distintas imágenes sobre el carácter de esa persona, y que cambios muy pequeños en la forma de presentar una fotografía, ya fuera por haber sido tomada con un ángulo distinto de cámara, o por presentar una leve sonrisa del candidato, producía diferencias importantes en cómo era percibida esa persona afectando a cualidades personales como la integridad, competencia y agrado. La segunda conclusión fue que las distintas presentaciones en la apariencia de un candidato pueden afectar a la decisión de voto; mientras que el tercer resultado sugiere que si se presenta adecuadamente la imagen pública de un candidato, durante una campaña electoral, es posible manipular la imagen que se está proyectando en el electorado.

Este estudio pone, sobre todo, en evidencia que no hay que infravalorar la actuación del marketing político a la hora de crear una imagen para un partido y que el significado político de las dimensiones no-verbales, que un candidato presenta, juega un importante papel en lo que el público decide.

\section{LA IMAGEN DEL LÍDER PROYECTADA POR LA TELEVISIÓN}

En la argumentación de los epígrafes anteriores se pone de manifiesto la importancia de crear una imagen para el líder político, pero no podemos olvidar que la imagen proyectada por el líder en cada una de sus apariciones televisivas depende, en ocasiones, del control político en las em- 
presas informativas. Baste para ello, referirse a las investigaciones realizadas por Semetko y Díez Nicolas (1999: 151-201), en las elecciones legislativas de 1993 y 1996 en nuestro país, o el trabajo más reciente dirigido por S. Berrocal (2003: 245-279) en los comicios de 2000.

Si en 1993 y 1996 el canal estatal TVE-1 y Tele 5 beneficiaban al Partido Socialista Obrero Español, mientras que Antena 3 daba un trato más favorable al Partido Popular, en las presentaciones de las noticias referidas a la campaña política. Durante las elecciones legislativas de 2000 con TVE-1, bajo el gobierno del PP, las afinidades políticas cambiaron.

El análisis del tratamiento concedido a los principales partidos políticos en los informativos de TVE-1, Antena 3 y Tele 5 durante la precampaña y la campaña electoral, en los comicios de 2000, condujo a los siguientes resultados: el candidato a la presidencia de gobierno que más tiempo de presencia tuvo en pantalla fue José $M^{a}$ Aznar: el $40 \%$. En segundo lugar se situó Joaquín Almunia: $37 \%$ del tiempo total. Francisco Frutos logró el 16\% del tiempo, y todos los candidatos presidenciales de otras formaciones políticas, sólo consiguieron en total el $7 \%$ de la atención televisada. Tele 5 fue la única de las tres cadenas que incumplió la tendencia general expuesta, al dedicar a Almunia un 20 \% de información más que a Aznar. Pero además, atendiendo a los datos totales sobre los valores asociados a la imagen, José $M^{a}$ Aznar fue el líder que mejor imagen global presentó en las variables analizadas: credibilidad, atractivo y poder, mientras que la peor imagen fue la de Joaquín Almunia. En TVE-1 y en Antena 3, Aznar obtuvo sus mejores imágenes, y en Tele 5 la menos favorable. Almunia ofreció su peor imagen en Antena 3, una intermedia en TVE-1 y la menos negativa en Tele 5.

Este estudio que indica las desigualdades en el tratamiento informativo recibido por cada uno de los partidos políticos en los distintos canales de televisión, se ve reforzado por la investigación sobre "infoentretenimiento", realizada en las mismas elecciones (Berrocal, 2003: 281-307). Los programas analizados: Caiga quien Caiga y El Informal de Tele 5, y Las noticias del guiñol de Canal + , beneficiaron la imagen proyectada por el candidato del PSOE: Joaquín Almunia, mientras que el líder peor tratado resultó ser José $M^{\mathfrak{a}}$ Aznar, del Partido Popular, con valores negativos en todas las facetas examinadas: credibilidad, atractivo y poder.

Estos estudios, referidos al análisis de los programas informativos durante las campañas electorales de 1993, 1996 y 2000 en nuestro país, sugieren que no sólo es necesario "crear" al líder político perfecto en cada contexto, siguiendo las estrategias del marketing político, para lograr su triunfo; sino que además, la imagen proyectada por la televisión puede aumentar o restar fortaleza al candidato.

\section{CONCLUSIONES}

1. Los medios de comunicación, y en especial la televisión, han agudizado la personalización de la representación política y modificado la retórica del discurso político. Los líderes, a falta de proyectos políticos diferenciados, emiten imágenes que los medios recogen y presentan a la opinión pública. Los líderes políticos se convierten en actores de la política. 
2. En la actualidad, en las democracias occidentales se impone la figura del líder "transformador", aquel que no sólo moviliza al electorado a través de un discurso lógico y racional sino también emocional.

3. La política se convierte en comunicación, es más importante la propaganda que se hace del producto que el propio contenido. Los programa políticos disminuyen su eficacia, mientras que la gana el líder.

4. Para alcanzar el liderazgo político, ser alguien capaz de movilizar a un grupo o parte de la mayoría, hoy se necesita un conocimiento y dominio del medio audiovisual.

5. El marketing político trabaja en la creación del líder político perfecto. Las acciones, discurso y cualidades del político deben encaminarse a la creación de una imagen en la que el político resulte creíble, atractivo y que manifieste poder ante la opinión pública.

6. La imagen del líder, moldeada por los estrategas del marketing político, puede resultar reforzada o degradada dependiendo de la actuación neutral o parcial de cada canal televisivo.

A partir de estos resultados se podría pensar que triunfa en el electorado el mejor actor político televisivo, de hecho se establece una paradoja el candidato tiene que hacer compatible su imagen de hombre corriente con la de ser el candidato "perfecto". "Queremos que uno de nosotros, un ciudadano medio que nos conozca y nos entienda, presente su candidatura para presidente. Pero una vez elegido, le exigimos que tenga una fuerza, una visión y unos conocimientos por encima de esta media. Esperamos que el presidente proporcione un liderazgo poco común (Denton y Hollowey, 1996: 37).

Junto a esta visión, probablemente negativa, del líder político que triunfa gracias a su conocimiento y dominio del medio audiovisual, no podemos olvidar que cada contexto político marca la necesidad de una determinada categoría de líder y que no basta la imagen que el candidato genera sino como ésta es percibida y evaluada por cada uno de los electores, atendiendo a innumerables factores. Es indudable que hoy el marketing político trabaja en la creación del "líder perfecto", pero lo es también que cada uno de los votantes tiene la última palabra en su consideración política. De ahí, que si lanzáramos la pregunta ¿quiénes son líderes políticos en la actualidad? Las respuestas no serían coincidentes.

\section{REFERENCIAS BIBLIOGRÁFICAS}

- Agranoff, R. (1972): The new style in election campaigns, Boston: Holbrook Press.

- Arceo, J.L. (1982): Cómo ganar unas elecciones, Madrid: Fomento de Bibliotecas.

- Campbell, A., Converse, P.E., Miller, W.E., Stokes, D.E. (1960): The American Voter, Nueva York: John Wiley. 
- Berlo, D.K., Lemert, J.B., Mertz, R.J. (1969): "Dimensions for evaluating the acceptability of messages sources", en Public Opinion Quarterly, no 33 .

- Berrocal, S. (2003): Comunicación política en televisión y nuevos medios, Barcelona: Ariel.

- Burke, K. (1962): A grammar of motives and a rethoric of motives, Cleveland: World.

- Collins, B.E., Ashmore R.D. (1970): Social psychology. Social influence. Attitude change, group processes, and prejudice, Reading Mass: Addison-Wesley.

- Costa, J. (1992): Imagen pública. Una ingeniería social, Madrid: Fundesco.

- De Cora, J. (1991): Manual del perfecto político, Madrid: Espasa Calpe, Crónicas de Hoy.

- Denton, R.E., Holloway, R.L. (1996): The Clinton Presidency: images, issues and communication strategies, Wesport: Praeger.

- Díez Nicolas, J., Semetko, H.A. (1999): "Los programas de noticias de televisión y las campañas electorales de 1993 y 1996: propiedad, contenido e influencia", en Muñoz-Alonso A., Rospir, J.I.: Democracia mediática y campañas electorales, Barcelona: Ariel.

- Hovland, C.I., Janis, I.L., Kelley, H.H. (1953): Communication and persuasion, New Haven: Yale University Press.

- Lazarsfeld, F.P., Berelson, B., Gaudet, H. (1944): The people's choice. How the voter make up his mind in a presidential campaign, Nueva York: Columbia University Press.

- Lazarsfeld, F.P., Berelson, B., McPhee, W.N. (1954): Voting: a study of opinion formation in a presidential campaign, Chicago: Chicago University Press.

- Louden, A. D. (1990): "Image construction in political spot advertising: the hunt/helms senate campaign, 1984" (tesis doctoral), University of Southern California.

- Marín, B. (2003): "Debates electorales por televisión", en Berrocal, S. (coord.): Comunicación política en televisión y nuevos medios, Barcelona: Ariel.

- Martín Salgado, L. (2002): Marketing político. Arte y ciencia de la persuasión en la democracia, Barcelona: Paidós.

- McCroskey, J.C. (1972): An introduction to rethorical communication, Englewood Cliffs: Prentice-Hall.

- McGinnis, J.(1972): Cómo se vende un presidente, Barcelona: Península.

- McGuire, W.J. (1969): "The nature of attitude and attitude change", en Lindzey, G., Aronson, E. (comp.): The Handbook of Social Psychology, vol. 51. Reading, Mass: Addison-Wesley.

- Muñoz-Alonso, A., Rospir, J.I. (1999): Democracia mediática y campañas electorales, Barcelona: Ariel.

- Ortega, F. (2003): "Una simbiosis compleja políticos y periodista", Telos, no 54.

- Perry, R. (1986): Elecciones por ordenador, Madrid: Tecnos.

- Popkin, S.L. (1990): "Information shortcuts and the reasonig voter", en Groffman, B. (ed).: Information, participation and choice. An economic theory of democracy, The University of Michigan Press: Ann Arbor. 
- Ramonet, I. (1994): "Del canal único y monopólico al caleidoscopio televisivo", en Huertas, F. (comp.): Televisión y politica, Madrid: Universidad Complutense.

- Séguéla, J. (1982): Hollywood lava más blanco, Francia: Flammarion.

- Rosenberg, S.W., McCafferty, P. (1987): "The image and the vote. Manipulating voter's "preferences", Public Opinion Quarterly, vol. 51, pp. 31-47.

- Trent, J.S., Friedenberg, R.V. (2000): Political Campaign Communication, Westport: Praeger.

- Weaver, D.H.: "Canalización mediática ("agenda-setting") y elecciones en Estados Unidos", en www.ucm.es/info/per3/cic/cic3ar12.htm, consultado el 12/1/2003.

- Weber, M. (1968): Economy and society, vol. 1, Nueva York: Bedminster Press. 